\title{
ethic@

\section{A DEMANDA RACIONAL DA ÉTICA DE KANT NO INÍCIO DE 1760}

\section{THE RATIONAL DEMAND OF KANT'S ETHICS \\ IN THE BEGINNING OF 1760}

\author{
BRUNO CUNHA ${ }^{1}$ \\ (UFSJ, Brasil)
}

\begin{abstract}
RESUMO
Meu objetivo nesse trabalho é apresentar uma linha distinta de interpretação do problema moral em duas das principais obras do jovem Kant, a saber, a Investigação sobre a Evidência e as Observações sobre o Sentimento do Belo e do Sublime. Em contraposição à leitura tradicional, tento mostrar que, ao analisar a relação entre os aspectos formais e materiais da moralidade, somos capazes de constatar que existe, de fato, uma demanda racional subjacente ao problema ético nesse contexto. Isso mostra, por conseguinte, que ao invés de representar uma mera reprodução da moral britânica, esses escritos retratam um momento de transição no qual Kant se liberta em grande medida da influência escolástica, para investigar mais profundamente o conceito primário de obrigação moral.

Palavras chave: ética; sentimento; razão; obrigação; jovem Kant.
\end{abstract}

\begin{abstract}
My aim in this paper is to present a distinct interpretation of the moral problem in young Kant's major writings, namely, Preisschrift and Observations on the Feeling of the Beautiful and the Sublime. In contrast to the traditional reading, I will try to stress, that from analysis of the relation between the formal and material aspects of morality, we are able to verify that there is, indeed, underlying these writings, a rational demand of ethics. Therefore, we can remark that these writings, more than a mere reproduction of British morality, represent a moment of transition in which Kant frees himself from scholastic influence, to investigate in another way the primary concept of moral obligation.
\end{abstract}

Keywords: ethics; felling; reason; obligation; Young Kant

\section{Considerações iniciais}

Devido ao caráter dos problemas filosóficos tratados no período pré-crítico, é de se admitir a dificuldade em se perceber o modo como se constituiu o pensamento ético de Kant em suas origens. Quando levamos em conta apenas as publicações desse contexto, deixando de lado todo material adicional que foi publicado apenas posteriormente, no século XX, não é de se surpreender que pareça incompreensível a forma como se dá a 
emergência do pensamento moral kantiano. Ao nos atermos apenas a essas fontes, sem uma análise mais acurada, a única coisa que parece evidente a partir delas é o exato momento em que Kant promove a transição de um modelo empírico de ética, baseado essencialmente na doutrina do sentimento moral, para uma concepção da moral puramente racional tal como se percebe no início de 1770 em sua Dissertação Inaugural. Dessa forma, fundamentada sobretudo nas evidências textuais da primeira metade de 1760, dentro da literatura, formou-se uma tradição interpretativa, cuja concepção retratou a ética kantiana desse período como um tipo de reprodução da doutrina do sentimento moral de Hutcheson e Shaftsbury. Diante disso, meu objetivo nesse artigo é argumentar, em contrapartida a essa interpretação, que existe, de fato, uma demanda racional por detrás dos primeiros esforços kantianos mais substantivos em torno do problema ético. Para levar adiante esse objetivo será necessário apresentar uma interpretação distinta da ética kantiana nos textos do início de 1760, dentre os quais estão incluídos a Investigação sobre a Evidência dos Princípios da Teologia Natural e da Moral e as Observações sobre o Sentimento do Belo e do Sublime, direcionando-a sobretudo a uma compreensão mais adequada da relação entre os aspectos formais e materiais da moralidade.

\section{A relação entre razão e sensibilidade na Preisschrift}

É notável que, no período pré-crítico, o problema ético só se enuncia verdadeiramente na filosofia kantiana a partir da última seção do ensaio intitulado Investigação sobre a Evidência dos Princípios da Teologia Natural e da Moral, conhecido como Preisschrift. Mesmo que, antes disso, seja possível constatar algum interesse moral-antropológico nas obras kantianas de "filosofia natural" da década de 1750, a Preisschrift ${ }^{2}$ foi o primeiro escrito publicado no qual Kant se propôs a analisar decididamente $^{3}$ o problema moral. Ao se indagar sobre a evidência dos primeiros princípios da filosofia moral, Kant vai tomar partido direto no debate ético moderno a respeito do conceito de obrigação, introduzido primeiramente no contexto alemão por Leibniz e Pufendorf ${ }^{4}$, mas levado adiante por Wolff, Baumgarten e Crusius.

No $\S 2$ de sua quarta consideração, Kant demonstra com clareza seu diagnóstico sobre o atual status da filosofia moral: "quero apenas indicar quão pouco conhecido ainda é o próprio conceito primário da obrigação e, portanto, quão distante se deve estar, na 
filosofia prática, de fornecer a distinção e segurança dos conceitos fundamentais e dos

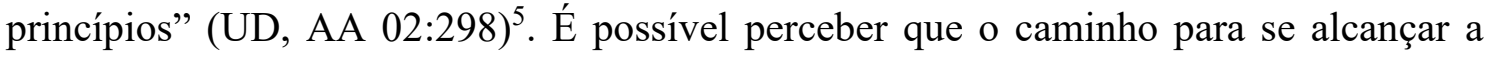
evidência e a clareza desse conceito primário se relaciona diretamente com a forma como somos capazes de compreendemos racionalmente os tipos de necessidade moral e as fórmulas sobre as quais se baseia nosso dever de fazer ou deixar de fazer algo. Desse modo, para Kant, "todo dever expressa uma necessidade da ação e é suscetível de um duplo significado" (UD, AA 02:298), expresso nos seguintes enunciados: "[a] saber, devo fazer algo (como um meio), se desejo alguma coisa (como fim); ou devo fazer imediatamente alguma coisa (como um fim) e levá-la a efeito" (UD, AA 02: 298). Como Crusius já havia estabelecido, nas linhas de sua Instrução de uma Vida Racional, a submissão a uma obrigação não significa somente assumir um motivo qualquer para agir, pois uma compulsão externa é capaz de excluir toda necessidade da ação ${ }^{6}$ (CRUSIUS Anweis. 1969, $\S 133)^{7}$. Isto é, agir por esperança, recompensa ou medo decreta a completa supressão da necessidade moral. Kant interpreta, à maneira de Crusius, essa necessidade vinculada aos meios ${ }^{8}$ como uma "necessidade problemática", porque ao invés de uma obrigação, ela indica "apenas um preceito como resolução de um problema (UD, AA 02:298) ${ }^{9}$. Então, no limiar de sua compreensão madura dos imperativos ${ }^{10}$, Kant sustenta a convicção de que "todas as ações são contingentes na medida em que a moral as prescreve sob as condições de certos fins, e não podem chamar-se obrigações enquanto não forem subordinadas a um fim necessário em si”.

Contudo, apesar da clara colocação do problema, é perceptível que nesse ponto o conceito de uma necessidade racional dos fins ainda não se encontra bem compreendida. Esse fato explicita-se quando Kant assume, sem apresentar uma citação direta, os exemplos de Wolff e Crusius como referência para seu problema. Eis os dois imperativos: "devo promover a maior perfeição como um todo" ou "devo agir conforme à vontade de Deus". Dentre "essas duas proposições, qualquer uma que subordinasse toda a filosofia prática, e ela deve ser regra ou fundamento da obrigação, então tem de comandar a ação como ação imediatamente necessária, e não como ação sob a condição de certo fim”. Para que um princípio seja assumido como regra da obrigação, portanto, ele deve ser capaz de proporcionar uma determinação imediata da ação (CRUSIUS Anweis. 1969, § 133) ${ }^{11}$. Apesar de ter sido Crusius aquele que sugeriu um novo tipo de compreensão da racionalidade prática como fim em si estabelecida em um caminho estritamente formal, é 
interessante perceber que Kant vai rejeitar seu princípio teológico como regra formal suprema da moralidade a favor de um imperativo de dupla estrutura que, aparentemente, não é nada mais do que expressão do imperativo wolffiano. "[D]epois de ter pensado muito", Kant vai conceber que "o primeiro fundamento formal de toda obrigação" encontra-se nas regras formais do agir e do abster-se de agir aos moldes de Wolff: "[a]ja da forma mais perfeita que puder [...], deixe de fazer o que te impede de alcançar a máxima perfeição" (UD, AA 02:299). Contudo, este princípio prático formal, da mesma forma que os princípios formais do conhecimento teórico, parece incapaz de preencher sozinho as demandas do imperativo ético, levando Kant a reconhecer a necessidade de alguns princípios materiais na filosofia prática ${ }^{12}$. Ora, da mesma forma que "nada decorre dos primeiros princípios formais de nossos juízos sobre o verdadeiro" sem os últimos, é preciso considerar agora que "tampouco nenhuma obrigação particular determinada decorre unicamente dessas duas regras do bem, se a elas não estiverem vinculados princípios materiais indemonstráveis do conhecimento humano" (UD, AA 02:299). De forma mais detalhada, Kant explica que "somente em nossos dias começou-se a ver que o poder de representar o verdadeiro é o conhecimento, mas aquele de ter a sensação do bem, o sentimento, e que ambos não devem ser confundidos". Assim como existem conceitos de objetos que não podem ser desmembrados no que concerne ao conhecimento teórico da verdade, o sentimento moral é uma experiência através da qual um bem não derivável é identificado, não no sentido de uma coisa em si, mas apenas em relação ao sujeito que sente. Nesse sentido, Kant nos fala de "um sentimento irresolúvel [unauflösliches Gefühl] do bem (este nunca é encontrado absolutamente em uma coisa, mas sempre de um modo relativo a um ser dotado de sensação)" (UD, AA 02:299). Tratase de um tipo de experiência de aprovação moral através da qual deve ser possível derivar o juízo "isto é bom”. É algo simples, imediato e, portanto, do ponto de vista práticoteórico, "completamente indemonstrável". A consciência imediata do bem, desse modo, deve ser concebida como um "efeito imediato da consciência do sentimento de prazer junto à representação do objeto" (UD, AA 02:299).

Kant revela nas linhas finais de sua apresentação que foram "Hutcheson e outros" que "forneceram, sob o nome de sentimento moral, um ponto de partida para belas observações" (UD, AA 02:300). Essa aberta referência a Hutcheson e aos moralistas ingleses na Preisschrift certamente foi, junto à menção apresentada no Anúncio do 
Programa de suas Preleções do Inverno de 1765-66, um dos pontos mais relevantes para o direcionamento das primeiras tendências interpretativas acerca do desenvolvimento. Ainda sem o acesso às fontes completas do schriftlicher Nachlass, estas tendências compreenderam que, sob a orientação dos ingleses e de Rousseau, Kant ocupou-se tão somente com uma análise psicológica e antropológica da moralidade até 1770, quando explicitamente promoveu um brusco rompimento com a noção do 'sensus moralis' no $\$ 9$ de sua Dissertação Inaugural. Todavia uma compreensão mais profunda do caráter do problema, especialmente sublinhada pelas interpretações que apareceram na segunda metade do século XX, mostrou que a importância do conceito hutchesoniano de sentimento moral encontra-se no fato de que algumas de suas características, a despeito das limitações próprias do sensualismo, esclarecem de uma forma mais adequada o caráter categórico e imediato da obrigação, adequando-se, de uma forma plausível, às exigências da hipótese kantiana. Através do conceito de sentimento moral, enquanto realidade irredutível, Hutcheson havia reivindicado um direito próprio para a existência da consciência moral diante da inadequação da faculdade teórica. Segundo ele, a razão teórica não pode ser critério na aprovação de nossos motivos, porque seus juízos são letárgicos para a tomada de decisões. A razão enquanto uma atividade puramente lógica é capaz apenas de conectar ideias, mas não de influenciar diretamente o agir. Hutcheson critica abertamente o racionalismo exacerbado da modernidade e o alcance da razão dedutiva e hipotética em relação à experiência mais concreta e fundamental do bem. A modernidade legou ao esquecimento a função específica da vontade ${ }^{13}$ (HUTCHESON, Moral Phil., 1755, p. 38). Por isso, os sentimentos e afecções são acionados para suprir nesse campo os limites da razão (HENRICH, 1958, p. 61-62). O conceito de sentimento moral é capaz de representar esta experiência ética imediata, todavia, não a partir de um juízo, mas como um tipo de satisfação imediata. Portanto, pode-se dizer que o conceito de sentimento moral é especialmente atrativo, nesse caso, devido a seu caráter interno, essencial e inderivável ${ }^{14}$ (HENRICH, 1959, p. 63), que se adéqua plenamente a reivindicação kantiana tomada de Crusius acerca de uma experiência ética enquanto uma necessidade dos fins.

Pode-se supor que esses princípios materiais, na hipótese de Kant, assumem a função de se ligar ao princípio formal para que seja possível alcançar através disso um conteúdo determinado do bem a partir de uma experiência originária inderivável, 
resultando dessa relação um imperativo moral. Então, a ideia de princípios materiais e de obrigações específicas é acionada para mostrar o modo a partir do qual determinados modos de ação podem ser reconhecidos como obrigatórios (SCHMUCKER, 1961, p. 78). Dessa forma, Kant esclarece que as "muitas sensações simples do bem" - aquelas mesmas que são experimentadas nas ações que são representadas imediatamente como boas, sem referência a qualquer outro fim implícito e que por isso agradam por si mesmas sem se ligar com as consequências - sempre "se submete[m] à regra suprema formal e positiva da obrigação" (UD, AA 02:300). Compreende-se que um modo de ação perfeito é aquele que pode ser reconhecido através do sentimento porque ele é imediatamente bom. Quando uma ação é representada imediatamente como boa ou perfeita, sem que contenha qualquer outra perfeição que possa ser descoberta pelo desmembramento, ela é aprovada pelo sentimento como um bem imediato e, então, reconhecida como um princípio indemonstrável da obrigação. Exatamente nesse caminho, o modo de ação adequa-se, de maneira perfeita, ao princípio formal. "Por exemplo: 'ama aquele que te ama' é uma proposição prática que se submete à regra formal e positiva da obrigação, mas de maneira imediata". O "amor recíproco" é objeto de uma sensação imediata e simples do bem, porque agrada por si mesmo e não é um bem derivado. Uma vez que tal característica da ação "não admite desmembramento", sua legitimidade é acionada pela aprovação do sentimento, indicando que ele se subsume "imediatamente à regra universal das boas ações". O processo pode ser esclarecido da seguinte forma: o sentimento de prazer legitima ou aprova de forma imediata um determinado modo de ação, mas não de forma aleatória, porque ele reconhece que este modo de ação, se perfeito, precisa estar adequado ao princípio formal.

Para uma melhor compreensão da questão, devemos estar atentos para o caráter que a regra formal começa a adquirir no campo prático. Dentro da literatura secundária, os intérpretes, de um modo geral, compreenderam que a regra formal pronunciada por Kant é meramente uma repetição do imperativo de Wolff. Todavia, no Escrito sobre a Existência de Deus, Kant admitiu ter refletido durante anos antes de abandonar a definição da perfeição como consensus in varietate para aceitá-la como uma propriedade baseada na harmonização entre razão e desejo na criação de um estado determinado de coisas $^{15}$. Está claro que o pensador de Könisgberg se afasta nesse momento do sentido ligado ao fisicismo natural de Wolff (SCHMUCKER, 1961, p. 74), que interpreta a 
bondade como um aspecto ontológico da natureza. Aqui a regra formal já representa mais do que um meio para se extrair o bem natural, mas é um artifício para alcançar o bem como um fim em si racional e necessário da vontade. Percebe-se, todavia, que, nesse ponto, a regra ainda é vazia de conteúdo, sendo incapaz de proporcionar um fim para a vontade sem o auxílio do sentimento. Isto é, no estabelecimento da hipótese, a regra formal superior é destituída de qualquer conteúdo, exigindo os princípios concretos imediatos fornecidos pelo sentimento com o objetivo de tornar inteligível a exigência moral do imperativo (HENRICH, 1958, p. 64). Neste processo, a razão realiza uma abstração a partir do objeto de desejo imediato, ou seja, do sentimento, formando um conceito de bem indeterminado que deve se estabelecer, através do princípio formal, como fim da vontade (UD, AA 02:299). Todavia devemos estar atentos para o fato de que este processo acontece em uma via de duas mãos, pois ao mesmo tempo em que o conceito de perfeição contido no princípio formal deve ser uma representação abstrata do sentimento, este, como os exemplos de Kant nos esclarecem, deve representar a experiência concreta da ideia de perfeição exigida nesse princípio formal. Quando o imperativo exige a realização da perfeição, o conceito do bem é alcançado a partir da subsunção do conteúdo concreto do sentimento, proporcionando o fim imediato da vontade. Mas, nesse processo, este conteúdo concreto não pode ser identificado, de antemão, como o fundamento do princípio formal, porque é a ideia de uma perfeição contida no último que permite a experiência de aprovação que caracteriza a atividade do primeiro. Nesta hipótese, é preciso, todavia, considerar mais exatamente se é a razão que, de algum modo, constitui, através de seu conceito de uma perfeição como fim em si, o fundamento do sentimento ou, de outro modo, se é o fim em si, contido na experiência imediata do sentimento, que determina a finalidade do princípio formal e, portanto, da vontade. De fato, a obscuridade do problema é devidamente destacada através da dúvida kantiana das linhas finais do tratado. Kant admite que para "ser possível alcançar o maior grau de evidência filosófica nos primeiros princípios da moralidade", deve ser decidido "antes de tudo, se tão somente o poder do conhecimento ou o sentimento (o fundamento primeiro, interno do poder de desejar) estabelece os primeiros princípios na filosofia prática" (UD, AA 02:300).

Apesar do problema permanecer insolúvel ao fim do tratado, é visível que a hipótese de Kant se distingue da de Hutcheson, em primeiro lugar, ao empreender a 
tentativa de uma determinação categórica e incondicionada da obrigação e, também, ao introduzir um princípio formal da obrigação através do qual o conteúdo do sentimento moral adquire o caráter de dever. Hutcheson e os moralistas ingleses tratam apenas com o fato material. Em contrapartida, devemos observar que, embora Kant ainda não tenha sucedido em deduzir o princípio de judicação [principium diudicationis] da moralidade a partir da razão prática (HENRICH, 1958, p. 64), sua hipótese busca justificar como a demanda racional apresentada no princípio da perfeição como fim em si pode se transformar em uma experiência ética concreta. No entanto, é preciso admitir, a despeito disso, que uma resposta clara para essa questão só vai ser alcançada posteriormente depois da assimilação kantiana do pensamento de Rousseau.

\section{A exigência racional nas Observações sobre o sentimento do Belo e do Sublime}

Se de fato há uma demanda racional por traz da doutrina ética de Kant na Preisschrift, o que dizer, então, em relação ao seu mais popular trabalho, redigido por volta da mesma época, a saber, as Observações sobre o Sentimento do Belo e do Sublime? O título do trabalho leva-nos imediatamente a supor que Kant vai direcionar seus esforços para um tratamento exclusivo e substancial do tema da estética, aos moldes daquele empreendido no tratado de Burke ${ }^{16}$ publicado em 1757 sob o título de Investigação Filosófica da Origem de nossas Ideias do Sublime e do Belo, que se tornou amplamente conhecido na Alemanha, em 1758, através do recenseamento de Mendelssohn. Mas, ao contrário disso, Kant não apresenta propriamente uma teoria estética e sim uma primeira tentativa de elaborar uma antropologia, a partir da análise das diferenças de raça e gênero, caracterizada por um emergente interesse moral.

A falta de acesso às fontes completas do Nachlass, no entanto, conduziu os primeiros comentadores a uma equivocada interpretação do verdadeiro papel desse programa antropológico. Através desse novo procedimento, Kant decide começar suas análises pelas pressuposições históricas e antropológicas em suas investigações no campo da ética, o que parece concordar pouco com sua hipótese madura. Sem a genuína compreensão à qual algumas fontes do Nachlass nos dirigem, os primeiros intérpretes, Kuenburg, Foerster e Menzer, compreenderam que Kant assumiu o método psicológico, baseado na análise dos sentimentos, como o critério de uma ética normativa preocupada 
em resolver justamente o problema do dever. Como conseqüência, o decisivo problema ético da Preisschrift foi interpretado à luz do método de investigação proposto nas Observações. Disso resultou uma compreensão limitada e inadequada das teses principais que são desenvolvidas lá. Tanto Foerster quanto Menzer chegaram à conclusão de que, a despeito de toda a reivindicação racional do problema, as bases da moral são estabelecidas na consciência do sentimento. Esta posição foi seguida de perto por outros intérpretes, dentre os quais podemos citar Vleeschauwer, que afirma que, nesse contexto, a consciência do sentimento moral se apresenta claramente como o fundamento da ética (1962, p. 43). Em uma interpretação mais recente, Suzuki (2014, p.160-161) se alinha à interpretação tradicional ao defender que, embora as Observações apresentem claramente as influências de Burke e Hume tanto em relação à distinção entre o belo e o sublime quanto no que diz respeito à tipologia das qualidades morais, o opúsculo é essencialmente hutchesoniano na medida em que sua configuração "lembra bastante a da filosofia do sentimento moral". Conforme sua análise constata, o encaminhamento dado ao texto que vai das distinções estéticas às morais segue justamente a divisão das Investigações de Hutcheson, não havendo, de fato, um distanciamento qualitativo, na hipótese kantiana, entre as qualidades virtuosas e a verdadeira virtude (SUZUKI, 2014, p.167). Todavia, como Schmucker (1961, p. 63) sublinha, se realmente a pressuposição desses intérpretes é verdadeira, devemos aceitar que Kant, em pouco tempo, desde a Preisschrift, realizou praticamente uma inversão de marchas, abandonando a posição moral estabelecida lá como fruto de uma longa reflexão. Se nas Observações, o princípio da ética é, realmente, tratado somente em referência ao sentimento moral, isso mostra que toda discussão realizada com Wolff, Baumgarten e Crusius sobre as bases da obrigação, levando em consideração um princípio formal incondicionado como ideal de perfeição, foi totalmente abandonada.

Para uma interpretação adequada, é preciso estar atento para o caráter do texto, percebendo, antes de tudo, como nos sugere Schmucker, que Kant apenas desenvolve o tema moral nos limites de sua teoria estética, não demonstrando qualquer objetivo de desenvolver, em um caminho decisivo, a teoria moral introduzida anteriormente. Talvez, essa falta de aprofundamento filosófico encontre uma justificação apropriada nas admitidas intenções de Kant, reveladas nas considerações iniciais de seu prefácio, no qual ele abertamente afirma seu desejo de se comportar, no decorrer de sua investigação, 
somente a partir do ponto de vista do mero observador. Se é admissível que é difícil conceber, a partir do tratamento estético-antropológico apresentado no texto, como a virtude pode ultrapassar a categoria de mera máxima, devemos investigar em qual caminho as afirmações antropológicas e psicológicas de Kant, em Observações, podem ser consistentes com a sua posição na Preisschrift. Elas, de alguma maneira, apresentam alguma contribuição para a questão da demanda racional da ética que lá se enuncia? Elas podem nos dizer algo mais sobre o princípio objetivo da moral em sua relação mais próxima com o sentimento?

Kant inaugura a primeira seção da obra com uma breve apresentação e distinção dos conceitos do belo e do sublime. Enquanto o sentimento do belo nos alude um tipo de experiência "alegre e sorridente", em contraste, o sentimento do sublime - - é algo que desperta uma satisfação que vem acompanhada ao mesmo tempo de temor (GSE, AA 02:208). Essa distinção vai se deslocar, na seção que se segue, propriamente para a questão moral. Kant reconhece quatro tipos de motivações básicas na natureza humana. A primeira delas é descrita nos sentimentos de simpatia e complacência. Estas qualidades são certamente dignas de estima dentro da natureza humana e por isso podem ser descritas como "amáveis, belas e nobres". Mas, se por um lado, estas ações nos aparecem como belas, por outro, elas não podem ser identificadas com a verdadeira virtude. De acordo com Kant, somente uma motivação fundada sobre principios identifica-se com a virtude, resultando dela o profundo efeito estético do sublime: "apenas a virtude é sublime" (GSE, AA 02:215). Ao que parece, essa distinção justifica-se no fato de que as louváveis qualidades de sentimento e temperamento, tais como a simpatia, são em si cegas, sendo valiosas apenas quando se harmonizam com princípios. Elas apenas carregam consigo um significado contingente quando direcionam o homem para uma ação aparentemente correta, porque, na verdade, essas qualidades e disposições podem mover ações que contradizem as verdadeiras regras da virtude.

Essa observação vale, do mesmo modo, em relação ao sentimento de complacência. Em definição, a complacência [Gefälligkeit] é "uma inclinação a tornar-se agradável com os outros através da afabilidade, do consentimento aos seus desejos e da conformidade de nossa conduta com suas intenções". Todavia, como Kant observa, este sentimento "ainda não é base de uma verdadeira virtude" (GSE, AA 02:216), pois em um caminho indesejável, a complacência, quando despida de princípios, pode engendrar 
todos os possíveis vícios. Por exemplo, quando este sentimento é direcionado particularmente às pessoas que nos circundam muitas vezes se apresenta como uma injustiça para aqueles que não estão restritos ao nosso pequeno círculo. Quando esta amável sociabilidade, que se revela como uma bela inclinação em agradar os outros, não é regulada através de princípios superiores, torna-se tola (GSE, AA 02:217)

Do mesmo modo, Kant observa que as ações realizadas a partir de um terceiro tipo de motivação, o sentimento de honra e, de sua consequência, a vergonha, não são necessariamente justificáveis do ponto de vista moral. A opinião que as pessoas possuem de nós adquire grande importância e nos conduz a realizar muitos sacrifícios. Todavia, na medida em que o critério de valor de tais ações é retirado da opinião de outros, seus esforços não são de modo algum virtuosos. Isso faz com que o sentimento de honra, apesar de seu refinamento, produza algo semelhante à virtude, algo que, segundo as palavras de Kant, é apenas um "simulacro [Tugendsschimmer] de virtude". Aqui já encontramos uma fundamental distinção entre a verdadeira virtude e sua mera aparência. Kant já parece compreender, em ligação com a questão da Preisschrift, que a verdadeira disposição moral diz respeito a um estado interno da mente ${ }^{17}$ distinto daquilo que se depreende a partir das consequências e da natureza externa do comportamento. Segundo Ward (1972, p. 22), este já seria um prenúncio da distinção central da doutrina madura entre a legalidade e a moralidade das ações.

Apesar da clara exigência de se fundar a virtude "sobre princípios" (GSE, AA 02:218), percebemos, todavia, a reivindicação de Kant dos belos e nobres sentimentos a saber, a simpatia e a complacência, os quais ele denomina virtudes adotivas - como suplementos motivadores da virtude genuína. Kant compreende que tais sentimentos estão próximos à virtude e podem atuar, em alguma medida, como móveis auxiliares, porque eles são legitimados por um prazer imediato no objeto (GSE, AA 02:218). A exigência dessas boas qualidades auxiliares parece encontrar uma boa justificativa na questão antropológica levantada em sua cosmogonia dos anos de 1750, a saber, o problema da falibilidade moral. As virtudes adotivas devem substituir provisoriamente a verdadeira disposição virtuosa nas pessoas que ainda não são capazes de agir a partir de princípios, dirigindo-as às ações belas e nobres. Elas devem, em segunda instância, apoiar a força motivacional e o ímpeto dos verdadeiros impulsos morais, compensando e contrabalanceando, enfim, as ações na natureza humana, uma vez que todas as ações belas 
e virtuosas tendem a ser suprimidas pelas ações grosseiras comandadas por um quarto tipo de motivação, a saber, o egoísmo ${ }^{18}$. Podemos dizer, em suma, que essas qualidades auxiliares que se ligam aos caracteres da natureza humana são "implantadas pela natureza para suprir a ausência do 'sentimento moral universal"” (SUZUKI, 2014, p.162).

É notável, no entanto, que essas virtudes auxiliares distinguem-se do sentimento moral universal e das verdadeiras intenções virtuosas, porque elas permanecem, em sua essência, sempre vinculadas às paixões, que são fracas e cegas. Certamente, os indivíduos que atuam a partir dos instintos auxiliares são conduzidos a ações cujo o resultado, de algum modo, acontece em proveito do todo. No entanto, o resultado de suas ações é certamente inferior àquele que pode ser engendrado a partir daquilo que Kant chama de verdadeira virtude. Esta é identificada com princípios a partir dos quais as disposições são tornadas independentes da inconstância e da mutabilidade das situações. Observa-se, frente a isso, que há um claro contraste entre o sentimento ligado às paixões naturais, às quais os instintos morais se vinculam, e o sentimento que se refere a uma experiência ética genuína: “[o] fundamento nobre permanece e não está submetido de modo algum às circunstâncias das coisas exteriores. Tal é a propriedade dos princípios em comparação com as emoções que nos exaltam apenas em ocasiões particulares, e assim é o homem de princípios, oposto àqueles oportunamente conduzidos por um impulso bondoso e amoroso " (GSE, AA 02:221). Por isso, o sentimento que se vincula a princípios, quando "se eleva à sua devida universalidade, é sublime, mas também mais frio" (GSE, AA 02:216). Ao discorrer particularmente sobre seu caráter, Kant afirma que os verdadeiros princípios da virtude não são identificados com regras especulativas, mas, uma vez considerados imediatos, eles se estabelecem diretamente no coração de todos os homens. Trata-se daquilo que se define como o sentimento da beleza e da dignidade da natureza humana.

De fato, à primeira vista, o conceito da "consciência de um sentimento" como a fonte imediata e universal dos princípios da virtude parece se contrapor diretamente ao conceito racional de obrigação proposto anteriormente na Preisschrift. Por isso, os primeiros intérpretes destacaram que pouca ou mesmo nenhuma progressão foi observada nesse ponto do desenvolvimento ${ }^{19}$. Todavia, é importante notar que apesar de Kant caracterizar as bases dos princípios da virtude como um sentimento, como a leitura isolada do texto nos permite concluir, ao nos atermos ao contexto, percebemos que o 
filósofo não deixa de sublinhar alguns aspectos que apontam para uma progressão de sua perspectiva anterior. Este sentimento é caracterizado claramente como uma tendência ou inclinação universal em direção ao gênero humano (GSE, AA 02:216). Assim se, por um lado, a beleza da natureza humana é, como em Hutcheson, apresentada como o fundamento de uma benevolência universal que está associada diretamente ao amor e à atração que se pode sentir em relação aos outros, por outro lado, é decisivamente introduzido, nessa hipótese, um novo conceito que não está disponível no pensamento britânico. O conceito de dignidade é concebido aqui como o fundamento do respeito universal à natureza humana e já estimado como um valor em si. Quando o sentimento do sublime alcançar a sua mais alta perfeição, o homem se amará e se estimará apenas em referência àqueles aos quais se estende seu vasto e nobre sentimento (GSE, AA $02: 221$ ). Isto faz com que devamos ajudar a um "homem porque sofre, não porque é meu amigo ou conhecido, não porque eu creio que ele seja capaz de retribuir o benefício com sua gratidão" ${ }^{20}$ (GSE, AA 02:221), mas, na verdade, porque "ele é um homem e tudo o que acontece aos homens me diz respeito também". O amor e a dignidade ligam-se aqui diretamente ao fato da humanidade, como um todo, ser digna de respeito, o que deve proporcionar uma vinculação necessária entre todos aqueles que participam de seu conjunto. Isso justifica o motivo pelo qual uma ação deve ser concebida "a partir de um ponto de vista mais elevado" no qual subordinamos "a uma inclinação tão geral nossas inclinações particulares". Quando o homem procede assim, submetendo seu ato a uma meta tão universal, "seu proceder apoia-se no mais alto princípio de benevolência da natureza humana e é totalmente sublime, quer pela sua invariabilidade, quer devido à universalidade de sua aplicação". Dessa forma, em referência à Preisschrift, observamos que o fundamento essencial e formal da moralidade já pode ser vislumbrado na ideia da submissão dos impulsos naturais ao caráter social e universal exigidos pelo conceito de natureza humana, o que revela, por um lado, um momento estético, a saber, o da beleza, e, por outro, um teleológico expresso no respeito enquanto fim comum de uma comunidade. É interessante observar que aqui Kant apresenta pela primeira vez aquilo que em sua ética madura vai ser considerado como o único conteúdo possível para seu princípio formal. Como é visto na segunda fórmula do imperativo categórico, a fundação da moralidade e do princípio formal deve pressupor a dignidade de todo ser humano como um fim em si (GMS, AA 06: 428-429). É claro que a hipótese madura se distingue em 
um ponto fundamental, ou seja, Kant considera aqui, além da dignidade, também a beleza da natureza humana, ponto de vista que será rejeitado em sua doutrina madura.

Já se constata nessa hipótese, todavia, que o conceito da essência do bem ou da perfeição moral como fim em si, que está por detrás do princípio formal kantiano discutido anteriormente, adquire um sentido mais determinado. Esclarece-se, em um ponto de vista que já aponta para a ética tardia, que a virtude exige a subordinação de inclinações particulares e sentimentos naturais, como a simpatia e a complacência, a princípios universais que se ligam a beleza e a dignidade da natureza humana.

Torna-se possível, através dessas pistas, apercebermo-nos melhor do caráter adquirido na relação entre os aspectos formais e materiais da moralidade, bem como a função do sentimento moral como princípio suplementar. Na Preisschrift, o sentimento moral fora definido, a partir das categorias de simplicidade e insolubilidade, como uma experiência imediata de prazer e desprazer ou de aprovação e desaprovação moral. Está indicado lá, na apresentação dos exemplos do amor recíproco e da desobediência a Deus, que o critério dessa experiência de prazer deve ser objetivo e independente das inclinações particulares do sujeito. A validade objetiva do sentimento já está contida na simplicidade e insolubilidade da experiência e no objeto formal ao qual ele se vincula. Esse ponto é mais adequadamente destacado aqui na diferenciação entre o sentimento moral universal e os outros sentimentos morais básicos, como a simpatia. Kant esclarece que a "simpatia moral ainda não basta, todavia, para incitar a natureza humana inerte a ações em vista do interesse comum [...]"(GSE, AA 02:218). Prosseguindo, ele ainda explica: “[o] de constituição de ânimo sanguínea [...] tem grande simpatia moral [...]. Seu sentimento moral é belo, mas destituído de princípios e depende sempre da impressão atual que os objetos produzem nele" (GSE, AA 02:222). A simpatia observada na descrição do caráter moral do sanguíneo, portanto, está vinculada tão somente às disposições mais particulares e emocionais do sujeito. Constata-se, por outro lado, que o sentimento moral universal baseia sua objetividade em um critério mais abrangente e fundamental. Em outras palavras, este sentimento é acionado porque um tipo de bondade essencial interna pode ser identificada. A aprovação se vincula a um valor superior proporcionado pelo objeto formal cuja exigência é a universalidade. Dessa forma, a atividade do sentimento pode ser percebida, de um modo mais claro, como a de um princípio suplementar que atua de acordo com as regras de uma consciência formal imediata, objetiva e universal. Isso é 
uma evidência relevante, diante da interpretação tradicional, a favor do fato de que a experiência de aprovação e desaprovação, já nesse contexto, não pode ser concebida como a última instância no processo de julgamento moral $^{21}$.

Além disso, Kant reconhece os limites do sentimento moral universal em algumas situações. Abre-se espaço para se supor, dessa forma, que os princípios práticos supremos da disposição virtuosa ultrapassam a mera experiência do sentimento moral. Segundo Schmucker (1961, p. 108), a descrição kantiana do caráter melancólico do sujeito moral apoia essa afirmação, sugerindo que os princípios práticos da disposição virtuosa pressupõem a capacidade livre do agente moral, cuja atividade interna deve subordinar um universo inteiro de impulsos e inclinações ao sentimento moral. Remetendo-nos à antropologia moral da década anterior, esta atividade manifesta-se como autarquia - um tipo de impulso ou disposição - um ato de decisão pessoal através do qual o sujeito subordina todas as suas inclinações e ações à moralidade. Por isso, o comportamento do melancólico é apresentado não somente a partir de sua relação com os sentimentos da bondade e da dignidade, mas também a partir de características como a serenidade e a força da mente. Estas características estão ligadas à capacidade do sujeito de tomar decisões em vista de um propósito maior, a partir da consciência dos riscos envolvidos e das dificuldades. Sua personalidade está vinculada à grandeza da vitória e à autosuperação ${ }^{22}$, o que se manifesta, por fim, como firmeza e obstinação. A verdadeira virtude, portanto, liga-se a uma disposição interna, à qual Kant nos alude, a partir das características próprias do sublime, não apenas em sua descrição do caráter melancólico, mas também na comparação dos sexos. Aquele que possui o caráter melancólico possui um elevado sentimento da dignidade da natureza humana. Por isso ele estima a si próprio e considera cada homem como uma criatura que merece respeito. Seu coração nobre respira liberdade e suas ações, ao contrário das ações belas, não indicam "uma grande facilidade", mas representam "grandes esforços, dificuldades enormes" e, com efeito, "excitam a admiração".

Diante dessa situação, Kant já compreende, apoiado por Rousseau, haver a necessidade de uma educação para a restrição dos impulsos naturais indevidos, tendo como objetivo a preservação dos costumes, das ciências e das artes e, por conseguinte, para a realização plena da liberdade. O sentimento moral não é uma capacidade inata, mas uma predisposição que deve ser desenvolvida e cultivada a partir do trabalho da 
educação. O segredo desconhecido dessa educação consiste "em exercitar o sentimento moral", como aspecto essencial para a responsabilidade moral e para a liberdade no mundo.

A presente análise da natureza humana, à qual as Observações nos conduziu, mostra que a maior parte dos homens não está apta a submeter as inclinações decorrentes do amor de si aos princípios da liberdade implícitos na experiência do sentimento moral. Embora Kant reconheça a carência do comportamento de acordo com princípios, ele sublinha a importância de se considerar a variedade das manifestações de temperamento para a uma caracterização completa da natureza humana. Todas essas qualidades são pensadas como aspectos que, em seu papel social e em relação a sua participação no todo, podem contribuir, de alguma forma, à natureza humana. Como Ward nos sugere, em palavras que nos remetem à teodiceia da década anterior ${ }^{23}$, trata-se de considerar a diversidade extraordinária dos sentimentos e atitudes humanas, sejam boas ou más, como partes de um grande e sublime design no qual as partes individuais e defeituosas contribuem para a maior perfeição possível do todo. Todavia, diante desse variado extrato antropológico que mostra as motivações da natureza humana, Kant já pressupõe o papel de uma regra como critério restritivo para as ações por impulso, capaz de orientar mais adequadamente nosso livre-arbítrio. Assim, apesar de Kant destacar a incapacidade humana de julgar corretamente de acordo com princípios e temer o peso da responsabilidade moral, discriminada na consequência das ações por princípios, por fim, ele admite que todas as inclinações dominantes, em algum momento, devem ser submetidas ao julgamento de um tribunal que avalia as consequências da conduta a partir de um "ponto de vista estranho". Trata-se, em outras palavras, de considerar um ponto de vista fora de si para julgar a aparência da própria conduta e para avaliar qual efeito tem esta conduta em relação aos outros. Segundo Schilpp (1966, p. 75), a partir deste impulso secreto, elevamo-nos sobre nossas ações e interesses mais particulares, o que permite nos separarmos momentaneamente de nossa individualidade. Se, de fato, nesta situação, este procedimento ainda não é capaz de direcionar o comportamento em direção a uma necessidade propriamente categórica, ele, pelo menos, permite julgar mais objetivamente ou racionalmente o caráter das nossas ações. É certo que Kant ainda suplica por uma resposta mais clara sobre este ponto de vista no qual os contrastes podem efetivamente se harmonizar no quadro geral da natureza humana (GSE, AA 02:226-227). "Quando eu 
observo alternadamente o lado nobre e o lado débil do homem, então reprovo a mim mesmo de não poder colocar-me naquele ponto de vista em que estes contrastes, todavia, apresentam o grande quadro de toda a natureza humana de uma forma tocante”. Ele está se tornando cada vez mais lúcido, no entanto, de que esta resposta não está no conhecimento metafísico da natureza, mas se encontra decisivamente em uma compreensão mais profunda do homem, à qual Rousseau lhe fornece um modelo através de seu "homem natural".

\section{Considerações finais}

Essa investigação buscou ter mostrado, pelo menos em alguma medida, que, longe de ser meramente uma reprodução da moral empírica inglesa, como anteriormente se conjecturou, os escritos kantianos da primeira metade de 1760 podem ser interpretados como pertencentes a um momento transitório no qual Kant, libertando-se da influência escolástica, dá os primeiros passos substantivos em direção a uma posição independente no campo da ética. Dessa forma, na gênese de suas concepções éticas, Kant já pensa o problema moral a partir da dinâmica entre razão e sensibilidade, ou seja, da relação entre seus componentes formais e materiais, com o objetivo de encontrar os caminhos adequados para estabelecer as bases de um conceito incondicionado de obrigação moral. Podemos observar, portanto, em contrapartida a leitura tradicional, que distintamente de uma mera aceitação acrítica, o modo como Kant recebeu suas influências nesse momento converge plenamente com a maneira como o pensamento dos ingleses foi assimilado pela própria tradição alemã dos tempos do iluminismo, como nos ilustra a resenha que Moses Mendelssohn redigiu para o trabalho de Edmund Burke publicado em 1757 sob o título de Investigação Filosófica da Origem de nossas Ideias do Sublime e do Belo" [...] nossos vizinhos, e especialmente os ingleses, precedem-nos com observações filosóficas da natureza e nós os seguimos com nossas inferências racionais. " $(1762$, p. 290f, apud Kuehn, 1995, p. 379). Mas, se, decerto, devemos admitir que os escritos do início de 1760 possuem caráter transitório, na medida em que levantam o problema ético sem ser capazes de respondê-lo satisfatoriamente, é notável que, pouco tempo depois, no período situado entre 1764-65, já é possível identificar os traços mais essenciais de uma solução adequada, que prenuncia muito do que seria apresentado na Fundamentação da 
Metafísica dos Costumes, tanto em relação ao problema ético em torno da obrigação moral quanto à delimitação dos papéis da razão e do sentimento no campo da moralidade ${ }^{24}$. Este progresso pode ser confirmado, sobretudo, pelas decisivas Anotações kantianas nas Observações sobre o Sentimento do belo e do Sublime. 


\section{Notas:}

1 Professor Adjunto na Universidade Federal de São João del Rei (UFSJ), São João del Rei, M.

G., Brasil. e-mail: brunocunha@ufsj.edu.br

2 Dentro da literatura secundária, autores como Menzer (1898, p. 290) e Kuenburg (1929 p. 8f) não identificaram de forma relevante indícios de um problema ligado à moral nos escritos de filosofia natural da primeira década.

$3 \quad$ Schilpp (1966, p. 41).

4 Para a compreensão desse ponto consultar Schwaiger (2009) e Cunha (2015).

5 Para as obras de Kant, utilizaremos o modelo de referência da academia de Berlim.

$6 \quad \S$ 133: "Ademais o dever [Schuldigkeit] é distinguido de todas as coerções internas e externas. Pois o que quer que seja que somos coagidos a realizar, não temos em relação a isso ainda nenhum dever. Distinguimos dever, além disso, daquilo que se faz por medo ou esperança“.

$7 \quad$ Aqui segue-se o modelo de referência para as obras escolásticas.

8 É perceptível que essa colocação incide diretamente contra a teoria perfeccionista de Wolff, cujo caráter consequencialista e eudaimonista estabelece as ações morais apenas como um meio para se alcançar a perfeição máxima dos estados naturais internos e externos do homem, o que corresponde, para ele, à posse do Sumo Bem, a saber, a máxima virtude adequada proporcionalmente ao estado máximo de satisfação (Fil. Prat. U. $§ 374$ cf, E.A $\S 44)$.

$9 \quad$ Henrich (1963, p. 417) compreende que, nesse ponto, a crítica de Kant também se dirige a Crusius, pelo fato de ele aceitar dois modos de imperativos para a obrigação, o de virtude e o de prudência. Por outro lado, Schmucker (1961, p. 84) argumenta corretamente que somente o último imperativo é uma verdadeira obrigação para Crusius, pois a necessidade da ação ou abstenção diante da lei divina é rompida se nossas ações não corresponderem diretamente a ela (p. 160). Como ele salienta, essa obrigação é suficiente apenas a partir de um tipo de obediência pura, diferente do amor pela lei ou pelo desejo de felicidade. Henrich não está errado em dizer que a crítica de Kant também se dirige a Crusius, mas o ponto atenuante em relação a isso está exatamente em sua interpretação teológica do imperativo moral.

10 Nesse ponto, a distinção dos imperativos, na opinião de Schmucker (1961, p. 61), não só ultrapassa a teoria da obrigação de Wolff como alcança propriamente a estrutura do pensamento maduro de Kant. De fato, embora a solução do problema ainda não tenha sido dada, devemos admitir, junto com ele, que a articulação conceitual dos tipos de necessidade através dos imperativos não se difere em nada daquela apresentada na Fundamentação na forma dos enunciados dos imperativos categórico e hipotético, que estão divididos, por sua vez, em regras de habilidade e de prudência.

$11 \S$ 133: “O impulso da consciência é, portanto, meramente um impulso para reconhecer certos deveres [Schuldigkeiten], ou seja, obrigações universais que se devem observar mesmo quando não se quer considerar as vantagens e desvantagens que derivam delas, cuja transgressão Deus punirá [...]. Finalmente, o dever não é o mesmo do que aquilo que é simplesmente feito por amor. Pois todos os homens concordam com o fato de que um dever não pode ser o tipo de coisa que fica a nosso critério querer ou não fazer, ou, dito de outra forma, que a essência do dever possa desaparecer através de uma alteração em nossa vontade. Portanto não permanece nenhuma alternativa além da que diz que o dever é um fazer ou deixar de fazer que devemos observar por obediência a Deus enquanto nosso senhor, criador e mantenedor altíssimo por causa de Sua vontade. Existe, portanto, no impulso da consciência a essência genuína básica da obrigação legal. Pois a obrigação da lei deve ser o que move o subordinado a obedecer aos comandos do seu senhor". 

que, enquanto endossa a aceitação das regras do método analítico das ciências naturais em detrimento do método geométrico-dedutivo, ao mesmo tempo, já apresenta uma clara lucidez em relação à restrição do fundamento lógico - aparece na forma de se pensar a relação entre os princípios formais e materiais do conhecimento. Na Elucidação, os princípios da identidade e contradição foram introduzidos como os elementos formais e abstratos capazes de reger junto com os princípios de razão determinante e de sucessão os aspectos conceituais referentes à estrutura ontológica das coisas. Sem uma distinção substantiva entre fundamentos lógicos e reais, o problema do material foi conduzido e explicado totalmente como uma consequência da aplicação dos dois princípios lógicos e metafísicos. Segundo Ward (1972, p. 28), na Elucidação, os princípios lógicos da identidade e não contradição e o princípio metafísico da razão suficiente são capazes de juntos proporcionarem todo conhecimento do mundo. Na Preisschrift, todavia, à luz de sua nova proposta metodológica e da distinção efetiva dos fundamentos, Kant precisa admitir a necessidade de um improvável fundamento material do conhecimento em adição aos princípios formais, que é um " aspecto dado" que não pode ser reduzido à análise e dedução. Então, ele reavalia o estatuto dos dois primeiros axiomas fundamentais. De fato, sua importância é preservada, porque, para Kant, os princípios de identidade e de contradição ainda "constituem os princípios supremos e universais, em sentido formal, de toda razão humana" (UD, AA 02:294). Trata-se de princípios indemonstráveis de tal maneira que não é possível e nem necessário que suas características sejam explicitadas através do desmembramento mediante uma nota característica intermediária (UD, AA 02:294). Existem, como Kant indica, outras proposições indemonstráveis na filosofia, mas elas são proposições indemonstráveis de segunda ordem que se submetem de maneira imediata aos princípios formais primeiros. E uma vez que muitas delas trazem os fundamentos de outros conhecimentos, devem ser concebidas como fundamentos materiais do conhecimento humano.

13 É importante notar como as perspectivas de Crusius e Hutcheson se alinham em uma contribuição decisiva para a compreensão kantiana do problema moral. Hutcheson, em um caminho próximo a Crusius, compreende que a psicologia dos racionalistas não é capaz de discernir as diversas sensações da alma através de sua teoria da faculdade única (HUTCHESON, Moral Phil., 1755, p. 48). Aristóteles e os escolásticos já haviam compreendido, que além da faculdade teórica, havia a necessidade de se considerar uma outra capacidade fundamental do espírito responsável por aceitar ou rejeitar aquilo que é representado como bom ou mal (Passions and Afections, 1728, p. 30) (HENRICH, 1958, p. 61). Além disso, Kant percebe que o conceito do sentimento moral como experiência imediata é, de alguma forma, compatível com a ideia de uma obrigação como fim em si ensinada por Crusius.

14 Hutcheson (Enquiry, 1725, p. viii-vix) afirma (em terceira pessoa): [...] determinações para aprovar afecções, ações ou caracteres de agentes racionais que nós chamamos virtuosas, ele destaca pelo nome de senso moral. Seu principal objetivo é mostrar que a natureza humana não foi totalmente indiferente nos assuntos da virtude para formar por si observações concernentes à vantagem e desvantagem de ações e com efeito para regular sua conduta. A fraqueza de nossa razão e as ocupações nascendo a partir das enfermidades e necessidades da natureza humana são tão grandes que poucos homens poderiam formar aquelas grandes deduções da razão que mostram que algumas ações são totalmente vantajosas para o agente e as contrarias são perniciosas. $\mathrm{O}$ autor da natureza forneceu a nós de forma muito melhor para uma conduta virtuosa do que nossos moralistas parecem imaginar através de quase tão rápidas e poderosas instruções como aquelas que nós temos para a preservação de nosso corpo. Ele nos deu afecções para serem fonte de cada ação virtuosa; e fez da virtude uma forma adorável na qual podemos facilmente distingui-la de seu contrário $[\ldots]$.

15 Em algumas Reflexões, datadas de 1753-1754, juntamente com a crítica à caracterização do arbítrio divino, Kant havia deixado claro que o conceito de perfeição é mal compreendido. No escrito de 1763, o Único Argumento Possível para uma Demonstração da Existência de Deus, em uma referência clara em relação a isso, Kant rejeita o conceito tradicional de perfeição que "consiste no mais alto grau de harmonia em um" e admite, certamente devido às questões anteriores, ter despendido anos de dedicação em torno do tema: "[e]u despendi um longo tempo investigando cuidadosamente o conceito de perfeição, de forma geral e em particular" (BDG, AA 02:90). Esta profunda investigação, como ele próprio admite, foi de fundamental importância especificamente para o esclarecimento da questão moral. Ora, pois, em suas próprias palavras, um conhecimento mais preciso da perfeição "contém bem oculto em si o que é capaz de esclarecer a natureza de um espírito, nosso próprio sentimento e ainda os conceitos fundamentais da filosofia prática". Apesar das variadas aplicações linguísticas do termo, estas investigações profundas 
elucidaram seu significado fundamental. Este conceito "sempre pressupõe a relação de um ser dotado de conhecimento e desejo" (BDG, AA 02:90). Assim, ao afirmar a importância da natureza infinita de Deus na constituição das possibilidades, Kant também está preparado para responder a Leibniz em relação ao verdadeiro caráter da perfeição. Nesse sentido, ele prossegue: “[c]onsequentemente, as possibilidades das coisas mesmas, que são dadas através da natureza divina, harmonizam com seu grande desejo. Nesta harmonia, todavia, existe o bem e a perfeição" (BDG, AA 02:91). Kant, neste momento, rejeita claramente a concepção leibneziana da perfeição para entendê-la à maneira de Crusius, a partir da bondade. Agora, de um modo claro, a perfeição é entendida como o desejo consciente de produzir um estado racional de coisas e, do mesmo modo, como a existência de um estado de coisas legitimadas a partir de um desejo (SCHNEEWIND, 2001, p. 539).

16 Em seu recente livro, Suzuki (2014, p.60) observa que "se não há nenhuma dúvida sobre a influência do livro de Burke sobre Kant e a estética alemã do século XVIII, por outro lado é preciso reconhecer que ela seja menos decisiva para a compreensão do opúsculo kantiano - e do desenvolvimento de sua moral - que a leitura atenta que o autor fez de Hutcheson e Hume". Segundo o autor, "Kant combina o ponto de vista burkiano da divisão entre o belo e o sublime com o ponto de vista tipológico humano das qualidades respeitáveis e das qualidades amáveis". Apesar dessa semelhança, "o opúsculo tem uma configuração que lembra bastante a filosofia do sentimento moral", principalmente quando "segue a divisão das Investigações de Hutcheson, a primeira delas dedicada à ideia de beleza e a segunda à ideia de virtude".

17 Esse ponto é corroborado no ensaio uma Tentativa de Introduzir o Conceito de Grandezas Negativas dentro da Filosofia publicado no final de 1763, quase um ano antes da publicação da Preisschrift, mas concluído pelo menos seis meses depois deste. Nesse ensaio, Kant acredita que a despeito das aparências, a moral e, com efeito, o mérito e o demérito, diz respeito a uma operação interna da mente. A moralidade de uma ação deve ser concebida em função de forças internas que devem mover o ato, em vez de impulsos físicos externos e suas consequências no mundo. Muitas faltas por omissão, devido às suas consequências moderadas, são tornadas quase invisíveis pelo hábito ou pela cultura (NG, AA 02:183). Ora, isso explicita, segundo Kant, a impossibilidade dos homens deduzirem "com certeza o grau de disposição moral de seus semelhantes a partir de suas ações“" (NG, AA 02:200). Do mesmo modo que não se pode estipular se certas negações são verdadeiras oposições reais tão somente através da análise empírica da natureza, no campo da filosofia prática, não se pode avaliar a verdadeira moralidade, oriunda das oposições reais das forças motivacionais internas, tão somente através de suas consequências externas. É certo que a disposição interna do homem precisa superar as forças contravalentes do amor próprio. Todavia não somos capazes de inferir verdadeiramente o grau de tais forças ao ponto de estimarmos tanto a disposição quanto o valor moral das pessoas. O juiz e o tribunal para julgar nossa conduta encontram-se igualmente ocultos (NG, AA 02:200).

Schmucker (1961, p. 109)

19 Segundo Schilpp (1966, p. 80), esclarece-se, com essa hipótese, apenas que Kant deseja elaborar sua ética sobre princípios universais e necessários, cujas bases materiais estão estabelecidas na consciência de um sentimento. Suzuki (2014, p.165) segue muito da interpretação tradicional ao conceber que embora Kant reconheça, como Hutcheson, a diferença entre a verdadeira virtude e as demais, ele não empreende uma distinção qualitativa entre elas, já que, diferente do fosso criado entre a virtude e as boas qualidades em seu pensamento maduro, no opúsculo pré-crítico "a continuidade gradativa entre elas é possível". Apesar de Suzuki (2014, p.166-167) admitir, em algum ponto, que o caráter moral não se deixa absolutamente medir em termos quantitativos, ele enfatiza que os princípios da virtude dos quais fala Kant "são máximas de generalização ou universalização no sentido hutchesoniano de que a ação ou o afeto deve sempre se estender ao maior número de beneficiários". Para ele, esclarece-se, dessa forma, que "se de um lado a virtude verdadeira é diferente das virtudes de adoção, de outro não há distância entre elas, já que todas elas têm de ser aprovadas pelo sentimento [...]. A passagem entre um grau e outro é de ordem quantitativa, de uma quantidade que, uma vez mais, não pode ser dada pelo entendimento ou pela razão, pois é uma diferenciação no interior do sentimento". Com isso, ele conclui "que Kant é inteiramente fiel a Hutcheson". No entanto, nossa análise da Preisschrift parece mostrar que, nesse contexto, é duvidoso que Kant seja realmente um seguidor totalmente fiel de Hutcheson. 
Em sua leitura do texto, Suzuki (2014, p.163-164) enfatiza, de maneira correta, que a "compaixão é um sentimento bom, mas cego". Ele observa que o "exemplo utilizado é recorrente entre os pensadores britânicos" e se encontra principalmente em Hume: "ao se deixar levar por sentimentos de consideração para com os necessitados, o indivíduo compassivo estará 'em débito com um terceiro' e impedido, dessa forma, de cumprir com 'o dever estrito da justiça"'. Hume observa, portanto, que os indivíduos compassivos seriam prejudiciais do ponto de vista da utilidade pública. Certamente, tanto Kant quanto Hume percebem que o problema em torno disso está na impossibilidade de generalizar as ações benévolas e compassivas. No entanto, para Suzuki, enquanto Hume acredita que a razão seria o aspecto responsável por empreender toda a correção ou equidade das ações humanas, "no Kant pré-crítico ela é ainda feita pelo sentimento". Em sua opinião, isso se daria pela ampliação e extensão dos bons sentimentos ao maior número de indivíduos. No entanto, com essa posição, reduzimos a tese de Kant à de Hutcheson ou à de Rousseau, o que uma análise mais minuciosa do desenvolvimento, a partir de outras fontes, não nos permite reconhecer.

21 É notável que no Escrito das Grandezas Negativas, na aplicação do conceito ao problema moral, Kant já se mostra consciente da existência de uma lei positiva da obrigação na consciência e da função suplementar do sentimento moral. Schilpp (1966, p. 60) observa que o significado do sentimento moral vai se afastar decididamente de qualquer possibilidade de identificação com o conceito de Hutcheson, pois Kant vai relacioná-lo claramente com uma lei interna inata. Observar-se-á, com isso, um progresso na relação entre os aspectos formais e materiais da moralidade, mostrando que em pouco tempo os papéis da razão e do sentimento foram delimitados em resposta à dúvida que perfaz as considerações finais da parte moral do Ensaio Premido. De maneira geral, a apetição funciona sempre em referência a uma grande multiplicidade de estímulos ou fundamentos subjetivos. Todavia, se os prazeres em geral variam exponencialmente de acordo com a multiplicidade de disposições subjetivas das pessoas, a experiência do sentimento moral universal vincula-se necessariamente a um único fundamento, qual seja uma lei interna e objetiva: “[u]m animal irracional não pratica nenhum vício, mas esta omissão não constitui qualquer vício (demeritum). É que ele não transgrediu nenhuma lei interna. Ele não foi impelido a uma boa ação por meio do sentimento moral interno e assim o zero ou a omissão não são determinadas como a conseqüência de uma oposição" (NG, AA 02:183). A referência kantiana aos animais já explicita a exigência de uma lei interna racional que deve atuar como fundamento do sentimento moral. Para comentário, consultar a "Gênese da Ética de Kant" (2017).

22 A autarquia aparece como um conceito fundamental na caracterização antropológica do homem que se forma ainda nos anos de 1750. Para comentário, consultar “A Gênese da Ética de Kant” (CUNHA, 2017, p.46-47)

23 Aqui trata-se de uma referência à resposta kantiana à teodiceia na Nova Elucidação (1:404). Ver "A Gênese da Ética de Kant" (CUNHA, 2017, p.59-60).

$24 \quad$ Nas Anotações nas Observações sobre o Sentimento do belo e do Sublime, material apresentado pela primeira vez, em 1942, no volume XX dos escritos completos de Kant, editado por Gerhard Lehmann e publicado pela Academia de Berlim. Para comentário, consultar a Gênese da Ética de Kant. 


\section{Referências}

CUNHA, Bruno. A Gênese da Ética de Kant: o desenvolvimento moral précrítico em sua relação com a teodiceia. Liberars: São Paulo, 2017.

Wolff e Kant sobre obrigação e lei natural: a rejeição do voluntarismo teológico na moral. Transformação v.38, n.3, Marília: UNESP, 2015.

CRUSIUS, Christian A. Anweisung vernünftig zu Leben. Reimp. Hildesheim: Ed. G. Tonelli, 1969.

FRIERSON, Patrick. Introduction. Observations on the Feeling of the Beautiful and Sublime and Other Writings. Cambridge University Press: Cambridge, 2011.

HENRICH, Dieter. Hutcheson und Kant. Kant-Studien. v.49. Berlin: de Gruyter, 1957, p. 49-69.

1963, p. $\overline{404-431}$.

. Über Kants früheste Ethik. Kant-Studien. v.54. Berlin: de Gruyter,

HUTCHESON, Francis. An Inquiry into the Original of our Ideas of Beauty and Virtue, Londres, 1725.

Londres, . An Essay on the Nature and Conduct of the Passions and Affections.

1728.

KANT, Immanuel. Gesammelte Schriften. v. I-XXI, Edited by the Akademie der Wissenschaften. Berlin: Reimer (DeGruyter), 1910. . Escritos Pré-Críticos. São Paulo: Ed. UNESP, 2005.

KUEHN, Manfred. The Moral Dimension of Kant's Inaugural Dissertation: A New Perspective on the "Great Light" of 1769? Proceedings of the Eighth International Kant Congress. Milwaukee: Marquette University Press, 1995, p. 373-92.

KÜENBURG, Max. Der Begriff der Pflicht in Kants vorkritischen Schriften. Innsbruck: F. Rauch, 1927.

MENZER, Paul. Der Entwicklungsgang der Kantischen Ethik in der Jahren 1760 - 1785 - Erster Abschnitt. Kant-Studien. v.2. Berlin: de Gruyter, 1899, p. 290-322.

. Der Entwicklungsgang der Kantischen Ethik in der Jahren 1760 1785 - Zweiter Abschnitt. Kant-Studien. v.2. Berlin: de Gruyter, 1899, p. 41-104

SCHILPP, Paul Arthur. La Ética Pré-Crítica de Kant. Cidad Universitária: Universidad Nacional Autónoma de México, 1966. 
SCHNEEWIND, Jeromé. A Invenção da Autonomia: uma história da filosofia moral moderna. São Leopoldo: Editora Usisinos, 2001.

SCHMUCKER, Josef. Die Ursprünge der Ethik Kants in seinen vorkritischen Schriften und Reflektionen. Meisenheim: A. Hain, 1961.

SCHWAIGER, Clemens. The Theory of Obligation in Wolff, Baumgarten, and the Early Kant. Kant's Moral and Legal Philosophy. Cambridge University Press, 2009, p. 58-76.

SUZUKI, Márcio. A forma e o sentimento do mundo: jogo, humor e arte de viver na filosofia do século XVIII. São Paulo: Editora 34, Fapesp, 2014.

WARD, Keith. The Development of Kant's View on Ethics. New York: Humanities Press, 1972.

WOLFF, Christian. Gesammelte Werke. Edited by J. École et al. Hildesheim: Georg Olms, 1960ff. (Indicado por $W$ ) 